\title{
PENGARUH PEMANFAATAN AUDIO VISUAL DALAM MENINGKATKAN KEMAMPUAN KONGNITIF PESERA DIDIK
}

\author{
Nur Ayna ${ }^{1}$, Sunarwin ${ }^{2}$, Magdalena Dhema ${ }^{3}$ \\ Fakultas Pendidikan MIPA, IKIP Muhammadiyah Maumere \\ E-mail: nuraina1030@gmail.com,Soenarwin2011@gmail.com
}

\begin{abstract}
Problem solving abilities is purpose to knows the injhuenca of using andro visual in cognitve increasing of student. This research implemented in SMA Negeri 1 Talibura on semester two mi periodof 2019/2020. The populasion of this research is all the student of SMA Negeri I Talibura where the sample of the research is the student of ten class mia which 51 student with is class of mia 1 and class mia II. The interpretation of the sample is using tehnigve. This research as aform, of transparant eksperiment type with the design. The tehinige of data collection sheert and test. This research using analysis data technigne, thent is normality test homogenenity test and t-test. Normality test data refers to the data tosttribube with normaly and homogenity that is the data is homogen. Based on hypothesis testing using the t-test shows that the value of $t_{\text {count }}=3.14$, while $t_{\text {table }}=2.00$. This shows that the value of $t_{\text {count }}>t_{\text {table }}$ so that. it can be concluded that the audio visual media inflecaned to abblity of congnitive of the student of SMA Negeri I Talibura.
\end{abstract}

Keywords: Media audio visual, of congnitive abbility

\section{PENDAHULUAN}

Undang-undang No 20 Tahun 2003 tentang Sistem Pendidikan Nasional menyatakan bahwa pendidikan adalah usaha sadar terencana untuk mewujudkan suasana belajar dan proses pembelajaran agar peserta didik secara aktif mengembangkan potensi dirinya untuk memiliki kekuatan spiritual keagamaan, pengendalian diri, kepribadian, kecerdasan, akhlak mulia, serta keterampilan yang diperlukan dirinya, masyarakat, bangsa dan Negara.

Salah satu masalah yang dihadapi dunia pendidikan adalah masalah lemahnya proses pembelajaran, dimana dalam proses pembelajaran anak kurang didorong untuk mengembangkan kemampuan berfikir. Proses pembelajaran didalam kelas diarahkan kepada kemampuan anak untuk menghafal, otak anak dipaksa untuk mengingat dan menimbun tanpa dituntut untuk memahami materi yang diingatnya itu untuk menghubungkannya dengan kehidupan sehari-hari ( Joesoef, 2001 ).

Nur ayna ${ }^{1}$, Sunarwin ${ }^{2}$, Magdalena Dhema ${ }^{3}$

Peserta didik cenderung untuk menghafalkan rumus dan definisi saja tanpa ada pemahaman yang mendalam terhadap suatu materi kimia (Qomaliyah, Sukib, dan Loka, 2016). Pembelajaran kimia juga lebih banyak diarahkan untuk keberhasilan menempuh tes ujian yang hakikatnya lebih banyak menekankan pada dimensi proses kognitif yang rendah seperti menghafal konsep (Muderawan, dan Tika, 2013).

Berdasarkan wawancara peneliti terhadap guru kimia kelas X SMA Negeri 1 Talibura, salah satu masalah yang sering ditemui saat mengerjakan soal siswa terendan dalam melaksanakan pemecahan masalah dalam mengerjakan soal, serta jalannya belajar dalam ruagan ditujukan pada cara berfikir siswa agar mengingat, pikiran siswa dituntut agar memahami materi yang diberi.

Penelitian yang dilakukan oleh Eka Fitri Aprilia tahun 2015 dengan judul "Pengaruh Media Pembelajaran Audio Visual terhadap Hasil Belajar Peserta didik Kelas X pada mata pelajaran PAI di SMA Islam Soerja Alam Ngajum Malang", bahwa kemampuan pemahaman konsep kimia peserta didik pada kelas yang memperoleh pembelajaran audio visual lebih baik dari pada peserta didik pada kelas yang memperoleh pembelajaran konvensional. 
Selanjutnya penelitian yang dilakukan oleh Siti Akmaliah tahun 2014 dengan judul "Pengaruh penggunaan Media Audio Visual terhadap Hasil belajar siswa pada mata pelajaran ekonomi dikelas $\mathrm{X}$ MA Attakwa, dan berikutnya penelitian yang dilakukan oleh Septiana Utaminingrum tahun 2015 dengan judul : Pengaruh Media Audio Visual dalam pembelajaran Bahasa Indonesia pada keterampilan menyimak cerita siswa kelas $\mathrm{X}$ SMA di kecamatan Pandak Bantul Daerah Istimewa Yongyakarta.

Berdasarkan hasil observasi dan wawancara pendidik disekolah tersebut menunjukan bahwa pelajaran kimia yang telah dipelajari selama ini masih kurang dalam menumbuhkan keaktifan peserta didik. Dalam proses pembelajaran pendidik lebih banyak menjelaskan disertai dengan tanya jawab dan diskusi, dimana waktu belajar peserta didik digunakan untuk mendengarkan penjelasan pendidik dan mencatat materi. Akibatnya, dalam belajar peserta didik untuk mengingat metode, materi, dan angka-angka sudah tertera peserta didik termasuk rumus-rumus iya ketahui. Sementara ini, penilaian yang dilakukan pendidik masih sebatas pada penilaian hasil belajar saja tanpa memperhatikan dari segi proses. pembelajaran ini menunjang potensi siswa kurang dilakukan, maka dari itu dapat menyebabkan kemampuan kongnitif pada siswa kurang aktif.

\section{METODE PENELITIAN}

Metode penelitian yang dipakai pada penelitian ini adalah metode kuantitatif dengan menggunakan pendekatan eksperimen deskriptif. Dilaksanakan di SMA Negeri 1 Talibura, provinsi NTT, peserta didik kelas X mia 1 dan 2 SMA Negeri 1 Talibura dengan jumlahnya 51 siswa merupakan subjek dalam penelitian ini. Pengumpulan data menggunakan soal tes kemampuan kongnitif sebanyak 10 soal, serta wawancara dengan beberapa siswa menggunakan wawancara tidak terstruktur.

\section{HASIL DAN PEMBAHASAN}

Hasil Tes Kemampuan Kongnitif

Tabel 1.1 Data Pretest Kelompok Ekperimen dan Kelompok Kontrol

\begin{tabular}{lcc}
\hline & $\begin{array}{c}\text { Kelompok } \\
\text { Eksperimen }\end{array}$ & $\begin{array}{c}\text { Kelompok } \\
\text { Kontrol }\end{array}$ \\
\hline data siswa & 25 & 26 \\
Angka & 37 & 44 \\
Tertinggi & &
\end{tabular}

\begin{tabular}{|c|c|c|}
\hline \multicolumn{3}{|l|}{ Angka } \\
\hline \multicolumn{3}{|l|}{ Terendah } \\
\hline Rata-rata & 19,44 & 23,85 \\
\hline $\begin{array}{l}\text { Standar } \\
\text { Deviasi }\end{array}$ & 9,73 & 11,46 \\
\hline \multicolumn{3}{|c|}{$\begin{array}{l}\text { Tabel 1.2 Data Posttest Kelompok } \\
\text { Ekperimen dan Kelompok Kontrol }\end{array}$} \\
\hline & $\begin{array}{l}\text { Kelompok } \\
\text { Eksperimen }\end{array}$ & $\begin{array}{c}\text { Kelompok } \\
\text { Kontrol }\end{array}$ \\
\hline Data siswa & 25 & 26 \\
\hline Angka & 91 & 89 \\
\hline \multicolumn{3}{|l|}{ Tertinggi } \\
\hline Angka & 21 & 23 \\
\hline \multicolumn{3}{|l|}{ Terendah } \\
\hline Rata-rata & 67,08 & 54,00 \\
\hline Standar & 18,68 & 17,49 \\
\hline Deviasi & & \\
\hline
\end{tabular}

Hasil Observasi Kemampuan Kongnitif

Tabel 1.3 Rata-Rata Hasil

Observasi Kemampuan

Kongnitif Kelompok

Eksperimen

\begin{tabular}{|c|c|c|c|}
\hline No. & Indikator KPS & Skor & Kategori \\
\hline 1. & Mengamati & 83 & Tinggi \\
\hline 2. & Mengelompokkan & 70 & Sedang \\
\hline 3. & Menafsirkan & 86 & Tinggi \\
\hline 4. & $\begin{array}{l}\text { Melakukan } \\
\text { komunikasi }\end{array}$ & 70 & Sedang \\
\hline 5. & $\begin{array}{l}\text { Mengajukan } \\
\text { pertanyaan }\end{array}$ & 100 & $\begin{array}{l}\text { Sangat } \\
\text { tinggi }\end{array}$ \\
\hline 6. & $\begin{array}{l}\text { Mengajukan } \\
\text { hipotesis }\end{array}$ & 100 & $\begin{array}{l}\text { Sangat } \\
\text { tinggi }\end{array}$ \\
\hline 7. & $\begin{array}{l}\text { Merencanakan } \\
\text { percobaan }\end{array}$ & 66 & Sedang \\
\hline 8. & $\begin{array}{l}\text { Melakukan } \\
\text { persiapan } \\
\text { percobaan }\end{array}$ & 80 & Tinggi \\
\hline 9. & $\begin{array}{l}\text { Melakukan } \\
\text { percoban }\end{array}$ & 60 & Sedang \\
\hline 10. & $\begin{array}{l}\text { Melaksanakan } \\
\text { percobaan }\end{array}$ & 100 & $\begin{array}{c}\text { Sangat } \\
\text { tinggi }\end{array}$ \\
\hline
\end{tabular}


Tabel 1.4 Rata-Rata Hasil Observasi Kemampuan Kongnitif Kelompok Kontrol

\begin{tabular}{clcc}
\hline No. & \multicolumn{1}{c}{ Indikator KPS } & Skor & Kategori \\
\hline 1. & Mengamati & 50 & Rendah \\
2. & Mengelompokkan & 20 & Sangat rendah \\
3. & Menafsirkan & 66 & Sedang \\
4. & Melakukan komunikasi & 50 & Rendah \\
5. & Mengajukan pertanyaan & 0 & Sangat rendah \\
6. & Mengajukan hipotesis & 0 & Sangat rendah \\
7. & Merencanakan eksperimen & 58 & Sedang \\
8. & Menlakukan persiapan eksperimen & 62 & Sedang \\
9. & Melakukan eksperimen & 20 & Sangat rendah \\
10. & Melaksanakan eksperimen & 57 & Sedang \\
\hline
\end{tabular}

diketahui bahwa data tedistribusi homogeny dimana nilai $F_{\text {hitung }}<F_{\text {tabel }}$.

Uji normalitas

Tabel 1.5 Data Hasil Uji

Normalitas Dari Nilai Pretest

\begin{tabular}{lllc}
\multicolumn{5}{c}{ Kelas } & $\begin{array}{c}\chi^{2} \\
\text { Hitung }\end{array}$ & $\begin{array}{c}\text { Taraf } \\
\text { signifikan }\end{array}$ & $\begin{array}{c}\text { Deraja } \\
\text { kebebas }\end{array}$ \\
\hline $\begin{array}{l}\text { Kelas } \\
\text { eksperimen }\end{array}$ & 1,64 & $5 \%$ & $\mathrm{k}-3=3$ \\
$\begin{array}{l}\text { Kelompok } \\
\text { kontrol }\end{array}$ & 7,00 & $5 \%$ & $\mathrm{k}-3=4$ \\
\hline \multicolumn{5}{c}{ Tabel 1.6 Data Hasil Uji Normalitas } \\
pada Nilai Posttest
\end{tabular}

Berdasarkan hasil uji homogenitas pada nilai pretest dan posttest maka dapat
Penentuan hipotesis yang diterima didasarkan dari angka $t$ hitung dan $t$ tabel. berdas $x_{\text {rkan }}^{2}$ angkaterangan $t_{\text {hitung }}<t_{\text {tabel }}$ maka $\mathrm{H}_{0}$

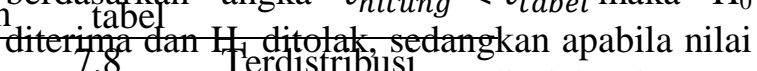
$t_{\text {hitung }}>t_{\text {tabebrmal maka }} \mathrm{H}_{0}$ ditolak dan $\mathrm{H}_{0}$ diterigna. Terdistribusi

Tabel 1,8 Data Hasil Uji t pada Nilai Posttest 
pemanfaatan vidio terhadap kemampuan kongnitif peserta didik. Menyimpulkan bahwa kemampuan pemahaman konsep kimia peserta didik pada kelas yang memperoleh pembelajaran audio visual lebih baik dari pada pesera didik pada kelas yang memperoleh pembelajaran konvesional. Elin Nur Hidayati (2016) juga telah melakukan penelitian dengan judul pengaruh media vidio terhadap kemampuan kongnitif peserta didik. . Hasil penelitian menunjukkan bahwa terdapat perbedaan hasil belajar yang signifikan dan sikap ilmiah antara peserta didik pada kelas eksperimen dengan peserta didik pada kelas kontrol.

\section{SIMPULAN}

Berdasarkan hasil penelitian melalui tema dampak pemanfaatan vidio dalam meningkatkan kemahiran kongnitif peserta didik materi pokok reaksi redoks disimpulkan kemampuan kongnitif siswa kelas $\mathrm{X}$ mia 1 dan 2 memiliki kriteria baik pada langkah memaha,mi banyak siswa tidak kewalahan sebab telah paham masalah dalam soal. Pada langkah merencanakan terdapat siswa yang tidak mencantumkan renvana taoi memahami rencana penyelesaina hendak digunakan dalam m,enyelesaikan masalah. Siswa yang berada pada kriteria baik 70,00-83,33 dengan presentasi $80 \%$ sebanyak 24 siswa, siswa yang berada pada kriteria cukup atau nilai 55,00-69,00 dengan presentasi $16,67 \%$ ada 5 siswa dan siswa yang berada pada kriteria kurang atau nilai 40,0054,99 dengan presentasi $3,33 \%$ ada 1 siswa.

\section{REFERENSI}

Arikunto, Suharsimi. (2016). cara eksperimen pada proses eksperimen. Jakarta: Rineka Cipta

Ibrahim . (2000). Kemampuan Kognitif. Jurnal Pendidikan
Sanjaya. (2009). Media vidio pada belajar artikel Kajian Pendidikan Kimia

Asnawir . (2002). Media Audio Visual. Jakarta: Indeks.

Yudhi Munandi. (2013). Media Audio Visual. Jakarta: EGC.

Azhar Arsyad. (2013). Efektivitas Pemanfaatan Media Audio visual sebagai Alternatif

Optimalisasi Model Pembelajaran. Jurnal Edukasi Elektro.

Sudjana dan Rivai. (2011). Pemanfaatan vidio pada Menunjukan keahlian Kognitif siswa. artikel IPA penanggulangan,

Desmita. (2006). Kemampuan Kognitif Siswa dalam Pembelajaran Kimia. Bandung: Kaifa.

Hudoyono. (2000). Indikator Kemampuan Kognitif Siswa. Bandung: Nuansa Cendekia.

Sulistyaningrum. (2011). Model Belajar Audio Visual. Jakarta: Rineka Cipta.

Eka Fitri Aprilia. (2015).akibat Media belajar vidio Tentang Hasil Belajar siswa Kelas $X$. Malang : Ngajum

Suwarto. (2007). kemunduran, pembeda, dan Reliabilitas Tes Menurut Teori Tes Klasik. Jurnal Pendidikan,

Siti Akmaliah. (2014). Pengaruh Penggunaan Media Audio Visual Terhadap Hasil Belajar Siswa Pada Mata Pelajaran Ekonomi Kelas X. Bandung: Remaja Rosda Karya. 